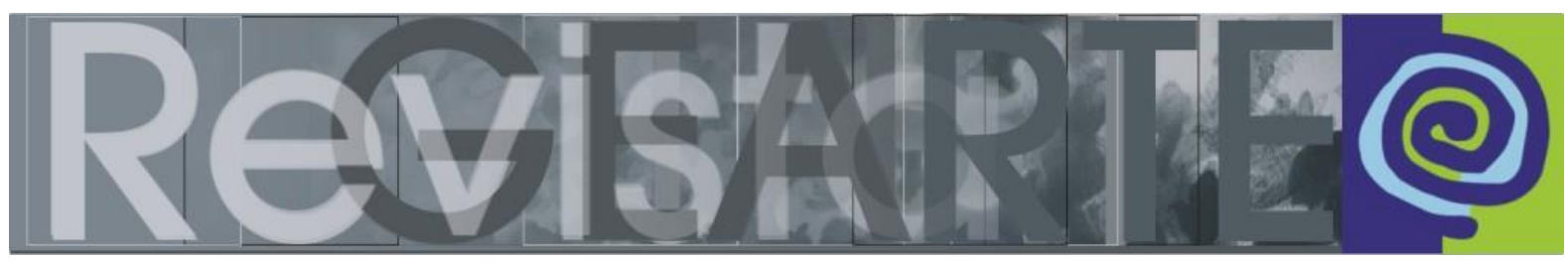

e-ISSN 2357-9854

Ensaio semiótico

\title{
Luz na escuridão: da leitura à apreensão de sentidos
}

Sandra Regina Ramalho e Oliveira (Universidade do Estado de Santa CatarinaUDESC, Florianópolis/SC, Brasil)

\section{Fiat luz}

Comecei a tirar melhores fotos quando ouvi alguém dizer "fotografia é luz". Não sei se é uma frase célebre, um dito de algum famoso fotógrafo, ou apenas a maior das obviedades. Mas é preciso que alguém diga ou, melhor, mostre para outro alguém, quem sabe para alguém que pode vir a saber, para que o conhecimento se dissemine. Perceba-se: mostre, e não ensine.

Isto porque o ensinar nem sempre coincide com o aprender; e mostrando-se o que se pretende que esse segundo alguém apreenda, talvez implique um aprendizado mais consistente. Luz lançada sobre a escuridão, em duplo sentido, pois lembra o momento bíblico no qual (Gênesis,1:3) Deus, lançando pela primeira vez a luz sobre a escuridão, diz: fiat lux et facta est lux, ou seja, faça-se a luz e a luz foi feita.

Neste artigo, retomo a preocupação com a leitura do mundo visual, que alguns chamam de leitura de imagens, outros de compreensão crítica, outros de interpretação e tantas outras denominações, com seus respectivos pressupostos teóricos. Retomo sempre no sentido de tornar tanto um processo metodológico de leitura de imagens quanto sua base teórica compreensível à maioria dos possíveis interessados. Não é à toa que o primeiro capítulo da minha tese de doutorado, defendida em 1998, intitulase $O$ acesso aos bens estéticos, quando não se falava em acessibilidade de qualquer tipo, fora dos âmbitos específicos. Para tanto, faço uma síntese dos desdobramentos de certas ideias lançadas nessa tese, as quais, no intuito de apresenta-las mais claras e de evitar que se restringissem às prateleiras das bibliotecas universitárias - ou aos congressos de semiótica ou arte, acabei por mostra-las sem pudor, transparentes 
demais, talvez. Parafraseando Barthes, querendo parecer óbvia, dei oportunidade para torná-las obtusas.

Abordo alguns pontos polêmicos e então apresento, para concluir, a leitura de uma imagem, a minha apreensão de sentidos a partir daquele modelo pensado na década de noventa do século passado, hoje ainda usado por professores nas escolas e, que eu saiba, em cursos superiores de arte, design, moda e jornalismo.

\section{Das obviedades}

Voltando a elas, além do fato de aprender que fotografia é luz, sobre ensinar igualmente se pode dizer muitas obviedades. A veiculação de saberes pode vir da construção no momento da interação professor/aluno ou "professor-aluno", ou reconstruída, quando oriunda de outros processos anteriores, mais sofisticados como a pesquisa científica, ou mais domésticos, como cozinhar o trivial. Há também o erro e o acerto, primitivo modo de aprender, processo solitário, eivado de desacertos e decepções, quando não, fonte de novas descobertas. Não que a pesquisa científica não tenha algumas características semelhantes, pois ambos são processos imprevisíveis, correspondendo ao regime de acidente, segundo Landowski ${ }^{1}$.

Por outro lado, nem sempre o óbvio é tão simples como pode parecer, pois o que assim parece, em geral, baseia-se na superficialidade ou na falta de uma devida interação com os fatos. Falo aqui da apreensão de efeitos de sentido das linguagens visuais de um modo geral, seja a fachada de uma edificação, um símbolo qualquer, um traje de gala, uma embalagem de um produto, um anúncio na rua ou na TV, ou um trabalho artístico. Trata-se da apreensão de efeitos de sentido, expressão que substitui com vantagens a outra expressão - leitura de imagens - que, sendo processo escolar ou não, deve ter cunho cultural e crítico.

O título da minha tese de doutorado, desenvolvida no Programa de PósGraduação em Comunicação e Semiótica da PUC/SP, sob a direção de Ana Claudia de Oliveira, intitula-se Leitura de imagens para a educação. Tratava-se de uma das

1 Há diversas publicações, mesmo em português, do semioticista francês Eric Landowski sobre o tema; destacamos a mais recente, Com Greimas: interações semióticas, 2017. 
dimensões propostas para o Ensino de Arte nas escolas brasileiras, a apreciação, juntamente com outras duas, a prática, e o estudo da arte como produto cultural e histórico. Entretanto, no que se refere à preparação de educadores, os currículos das licenciaturas pouco ou quase nada continham acerca dessa dimensão, relativa ao destinatário da imagem.

Embora tudo o que trata de especificidades hoje seja mal visto, num mundo contemporâneo sem fronteiras, ainda assim as ênfases em focos específicos nos ajudam a ultrapassar o caráter superficial inerente às generalidades. Atenta a isso e carregando a responsabilidade de professora de escolas nos então chamados I e II Graus, e em seguida, professora de licenciatura na Universidade ${ }^{2}$, eu me sentia pouco à vontade. Como lançar luzes sobre algo para mim nem sempre claro, não obstante ser detentora de um título de Licenciada em Arte e outro de Mestre em Educação?

Posteriormente à defesa do doutorado, cujas descobertas e dúvidas difundi por meio de aulas, orientações de dissertações e teses, artigos, livros, como o livro intitulado Imagem também se lể ${ }^{3}$, meu título mais procurado até hoje, aqui e em Portugal, observo os desdobramentos daquelas ideias. Após 20 anos da defesa da tese, faço algumas autocríticas. Revendo textos e discutindo com meus atuais doutorandos $^{4}$ e com duas doutoras ${ }^{5}$ cujos pós-doutorados supervisiono, surgiu do grupo a sugestão para que eu escrevesse sobre pontos pouco iluminados, tanto os que, devido à objetivações, sofreram interpretações distorcidas, como aqueles que merecem ser atualizados ou discutidos, dado o contato com outras ideias, ao longo desse tempo, em virtude de novos desenvolvimentos de teorias na arte, na educação e na semiótica. Em debates com meus mais próximos estudantes, percebi que nem sempre é óbvio o que me parece assim.

2 Centro de Artes da Universidade do Estado de Santa Catarina (UDESC).

3 Edições Rosari, 2005, 2010.

4 Airton Jordani, Ana Sabiá, Angela Palhano, Janaí Pereira, Luciano Buchmann, Rosanny Teixeira e Sandra Nunes, doutrorandos em Artes Visuais do Programa de Pós-Graduação em Artes Visuais (PPGAV/UDESC).

5 Cárlida Emerin e Luzinete Carpin Niedzieluk, em Estágio Pós-Doutoral no mesmo Programa, de 2016 a 2017. 
Também chegamos à conclusão, conjuntamente, que o responsável maior foi um artigo que escrevi, homônimo ao meu livro mais conhecido que é já bastante reduzido ${ }^{6}$, em densidade e extensão em relação à tese, no qual cheguei ao extremo em termos de simplificação, o que levou a distorções. Ou seja, como fui eu que escrevi aquele artigo, a responsável sou eu mesma que, no afã de dividir o que levara quatro anos fundamentando e produzindo, induzi os leitores a interpretações apressadas e a julgamentos superficiais, que não consideram as muitas camadas sobre as quais se apoia a proposta pedagógica teórico-metodológica para a leitura (ou apreensão) de imagens.

Impossível seria rever todo o arcabouço inicial, sua base teórica em termos de educação, arte e semiótica, das relações entre estas áreas, por si já tão complexas e extensas, além da formatação de um processo e, depois de tudo, atualiza-los. Assim sendo, parto de alguns pontos que geralmente suscitam mais críticas ou mais indignação, esta, de minha parte.

\section{Alguns dos pontos polêmicos}

O acesso aos bens estéticos é o título do primeiro capítulo da tese e encerra a síntese não só do problema de pesquisa, como de um compromisso de cidadania de minha parte. Minha busca da luz. O fato de tomar como objeto de estudo coisas fúteis ou supérfluas da sociedade capitalista em nada me afastam desse compromisso, ao contrário: desvelar estratégias de manipulação visual possibilitam tanto apropriar-se da decisão de consumir ou não determinados produtos, como assenhorear-se da condição também de cidadão, decorrente da criticidade e da emancipação resultantes de um processo análogo à alfabetização verbal, que chamo de "imagemização". Quase todas as nossas escolhas dependem da condição de iniciados na linguagem visual, ou nas linguagens estéticas, ao menos parcialmente, das escolhas do coração às da vida prática do cotidiano; daí sua imprescindibilidade para o exercício da

6 RAMALHO E OLIVEIRA, Sandra Regina. Imagem também se lê. In: DA ROS, Silvia Zanatta; MAHEIRIE, Kátia; ZANELLA, Andréa Vieira. (Orgs.). Relações estéticas, atividade criadora e imaginação: sujeitos e (em) experiência. 1a. ed. Florianópolis: NUP/CED/UFSC, 2006. p. 209-220. 
cidadania, no meu ponto de vista, a capacidade do exercício de escolhas, com liberdade.

Ainda nessa vertente de viés ideológico, ouço ruídos sobre uma espécie de insensibilidade, racionalidade irrestrita, ou negação do imponderável nesse modelo de leitura de imagem. O fato é que os críticos muitas vezes conhecem apenas superficialmente, ou um fragmento, da densa produção contemporânea da semiótica. Entre outras, aquelas oriundas dos esforços da École de Paris, sob a coordenação de A. J. Greimas, as quais resultaram, entre muitas outras publicações, em dois títulos autoexplicativos: Para uma semiótica sensível, de autoria de E. Landowski (2005) e Visualidade: entre significação sensível e inteligível, de Ana Claudia de Oliveira (2005), motivo pelo qual eu os cito.

Outra questão também diz respeito à minha permanente ânsia de partilhar o que aprendo; assim, cometi a suposta generosidade de enumerar etapas de um possível percurso flexível, no artigo já citado, o qual é síntese do homônimo livro em que já resumo algumas partes da tese. Daí tive o desprazer de ouvir alguém falar que trabalhava com o "método dos sete passos". Dada a polêmica nacional sobre o processo triangular, denominado e criticado sucessivamente por intitula-se metodologia, depois proposta, acabando como Abordagem Triangular, chamar de método seria uma blasfêmia. Embora no campo da Educação tudo o que se refere a qualquer coisa que pode ser metaforizado como receita de bolo seja execrado, no campo da semiótica trabalha-se a partir de modelos, que não são fixos nem acabados, mas possibilitam um mínimo de cientificidade. Assim, faltou, naquela época, esclarecer que um "modelo", em semiótica, sempre é flexível e nunca está pronto, possibilitando novos desenvolvimentos ou até reparos, em consonância com questões de toda ordem, das culturais até as relativas ao estágio de desenvolvimento das teorias. "Receita de bolo" eu cheguei a ousar e usar como metáfora, ou como uma provocação, exatamente para mostrar que não era o que chamam de receita. Mas parece que alguns não sabem o que é uma metáfora, nem quando se fala em "leitura" de imagens.

Outra polêmica tem a ver com texto versus contexto. Os entendimentos rasos deturpam o modelo viso-textual. No fecundo texto de E. Landowski (2001), intitulado 
O olhar comprometido, temos a argumentação do porquê de a semiótica discursiva contemporânea não mais se preocupar com os textos, fixos, mas com as interações in fieri, ou em presença, uma semiótica das relações interpessoais, intersubjetivas, mais adequadas à análise da arte contemporânea. Tive a oportunidade de apresentar oralmente, num dos Colóquios Anuais do Centro de Pesquisas Sociossemióticas/CPS, na PUC/SP, em uma mesa coordenada por E. Landowski, e de publicar no livro Do sensível ao inteligível: duas décadas de construção do sentido ${ }^{7}$, a importância de ainda se estudar o texto visual, como os elementos visuais são articulados para significar, quando se trata do ensino de arte. Não fui contestada.

O problema maior é aquele que acaba gerando o mal entendido de que "a semiótica não se preocupa com o contexto". Ora, desde o velho Saussure todos sabemos que qualquer linguagem é um fato social, ou seja, só tem sentido — em mais de um sentido - no contexto. Isto é um pressuposto e, talvez diante de tal obviedade, eu tivesse me aprofundado mais em outros aspectos, intrínsecos ao visual como linguagem, ou como texto, e não no contexto, ou nos contextos, até porque muitos outros campos do conhecimento se ocupam de estuda-lo, ou nos domínios da Antropologia, ou da História, ou da Filosofia, ou da Sociologia, da Psicologia ou dos Estudos Culturais, entre outros. Mas a Semiótica é o campo mesmo das linguagens. Assumindo uma espécie de déjà vu para a semiótica, fixei-me na noção de texto para tentar facilitar de algum modo "o acesso aos bens estéticos". Partindo da ideia de texto visual, empreendi então a busca de um modelo semiótico modificando aquele proposto por minha orientadora Ana Claudia de Oliveira, que teve a generosidade de me permitir faze-lo. Seu modelo propõe, para o estudo do texto visual, a análise de quatro formantes: eidéticos, cromáticos, topológicos e matéricos. Eu me ative a um constructo mais próximo de analogias com o texto verbal, para facilitar o uso na escola.

Inicialmente, é preciso preparar a imagem para a leitura, o que pode ser feito rapidamente apenas com o olhar pelos iniciados, ou com lápis e papel na mão pelos

7 RAMALHO E OLIVEIRA, Sandra Regina. Sentidos de uma teoria do sentido no campo das linguagens visuais. In: OLIVEIRA, Ana Claudia de. (Org.) Do sensível ao inteligível: duas décadas de construção do sentido. São Paulo: Estação das Letras e Cores, 2014. p. 195-210. 
noviços, como diria E. Landowski, o que inclui alunos de escolas, crianças, jovens, mas também adultos leigos que nunca tiveram a oportunidade de se apropriar com mais profundidade de bens estéticos. É recomendável procurar a estrutura básica da imagem (uma ou mais linhas, uma figura, etc.); e depois, buscar a configuração de esquemas visuais, que ajudarão a desconstruir a imagem, na procura de seus significados como que escondidos em linhas e formas evidentes, ou camufladas, ou sugeridas. A estrutura básica e os esquemas visuais ajudam no processo de leitura, pois a eles poder-se-á retornar inúmeras vezes, durante a análise.

Por analogia ao texto verbal, levando em conta o contexto das escolas brasileiras, de seus professores e alunos, adotei a subdivisão do texto visual em Plano de Expressão e Plano de Conteúdo, conforme preconizado por Louis Hjelmslev (2001), dimensões interdependentes, indissociáveis, separadas apenas provisoriamente, para efeitos de análise.

O Plano de Expressão é o que é perceptível aos sentidos, no campo do visual, à visão, outra obviedade; mas nem tanto, pois do concretismo à vídeo-arte convocamse outros sentidos para perceber um trabalho preferencialmente visual, já que a arte contemporânea se encarrega de desafiar até a existência de apenas cinco sentidos. Isto quer dizer que na análise, preconizo o levantamento inicial dos elementos constitutivos perceptíveis, sem associa-los ainda aos significados, aos efeitos de sentidos.

Ainda em analogia com o texto verbal, por ser o mais conhecido pelos alunos, os elementos constitutivos equivalem às categorias das palavras. Assim, verbo substantivo, adjetivo seriam equivalentes, para efeitos e estudos, a linha, cor, textura, sem correlação direta, mas considerando seus desdobramentos, ou seja, substantivo existe uma infinidade, assim como a cor, que ainda pode ter tom, matiz, brilho. Daí receberem o nome de elementos constitutivos: assim como sem palavras não há texto verbal, sem elementos do texto visual não há procedimentos relacionais, nem imagem.

Outro ponto a destacar: no desenvolvimento de experiências após a tese, percebi a existência de efeitos de sentido decorrentes não de elementos constitutivos, 
mas de certas condições da manifestação estética. Como não são constitutivos da imagem, chamei-os de "elementos significantes", pois atuam sobre seus efeitos de sentido. Refiro-me ao recorte, à moldura - no sentido amplo - e ao suporte, sobre os quais muito ainda se deve investigar.

No processo de leitura proposto, passa-se a observar, depois de identificados os elementos constitutivos e significantes, as relações entre eles. Seria a sintaxe do texto visual. Foi denominado de "procedimentos relacionais", pois se trata de buscar como o sujeito autor procedeu, relacionando os elementos constitutivos, para que o texto visual "dissesse o que diz". Da mesma maneira que o sujeito escritor articula palavras, por meio da sintaxe, para dar sentido ao conjunto do texto verbal.

Portanto, o Plano de Expressão é desmembrado em duas sub-dimensões, também indissociáveis na imagem: elementos constitutivos e procedimentos relacionais. Trata-se, aqui, não da introdução de mais um princípio ou conceitos semióticos, mas de conceitos básicos do ensino da arte, que vêm, ou deveriam vir, desde a Educação Básica: são os fundamentos da linguagem visual. Isto mostra o equívoco que cometem os que pensam que análises que atentam para a composição visual, seus elementos, estruturação e modos de ser são proposições semióticas.

O Plano de Conteúdo, por outro lado, é o campo semântico, onde se evidenciam os efeitos de sentidos decorrentes do Plano da Expressão; por este motivo são indissociáveis, pois não existe matéria, chamemos assim, sem efeitos de sentido, e não existe sentido (no sentido de significações) sem uma corporificação perceptível aos sentidos (no sentido dos cinco sentidos), mesmo que seja um ruído ou um odor.

Depende, então, do encontro das capacidades de significar do autor e do leitor os efeitos de sentido a serem apreendidos por alguém, ou a serem atribuídos por alguém a algo. Aqui não existem subdivisões, nem sugestões, nem dicas. Aqui o processo de leitura se dá dependendo da imagem, do leitor e dos esforços empreendidos para identificar os elementos constitutivos e os procedimentos relacionais no processo de desconstrução, na busca do seu potencial significante. $O$ criador de imagens concebe um sintagma, do mesmo modo que o curador o faz, isto é, procede a uma seleção, com critérios pré-definidos, estabelecendo uma narrativa. 
De todo modo, a imagem é o universo de qualquer leitura. Se dependêssemos exclusivamente dos dados externos e anteriores a sua existência, um trabalho de um autor desconhecido, seja uma publicidade ou uma inscrição rupestre, jamais poderiam ser objeto de algum tipo de leitura. Por outro lado, sem a contaminação de conhecimentos a priori, maior é o esforço para se apreender sentidos de uma imagem. A proposta vai também na contramão das leituras do senso comum, que quer logo partir para o Plano de Conteúdo (o quê isso quer dizer?), sem esgotar as possibilidades analíticas, estéticas e linguísticas que a própria imagem oferece. Não obstante, nada contra a que, após esgotar as possibilidades da leitura da imagem, busquem-se no contexto complementações ou reiterações. Afinal, contexto também é um texto ou textos, muito mais complexo, pela pluralidade e porque não está explícito como um texto em análise.

Uma outra crítica, se é que isto possa ser considerado crítica, refere-se ao fato de que o modelo de análise proposto poucas vezes adequar-se à diversidade da arte contemporânea. Assim, rotulam-no como modelo restrito ao modernismo. Concordo, em parte. $\mathrm{O}$ modelo destina-se à leitura de imagens, principalmente às imagens estáticas, imagens da arte, modernistas ou não, e de imagens estéticas não artísticas, encontradas no cotidiano. Ele pode ser útil a uma foto de uma performance, mas não à leitura da performance em si. Para certos tipos de eventos, principalmente os que se dão no tempo, a semiótica oferece outros recursos teórico-metodológicos.

Há ainda outro conceito a discutir. Na década de noventa passada, no âmbito do Programa de Comunicação e Semiótica da PUC/SP, falava-se em "códigos" para se referir às diferentes linguagens. $E$ assim procedi na tese, denominando de códigos as linguagens visual, musical, cênica e audiovisual. Devido à incompreensão de tantos que, com concepções do senso comum, entendem por código qualquer conjunto de caracteres simbólicos, ou seja, convencionados, passei a denominar o que chamara antes de código, de linguagem. Entretanto, esse entendimento não é de aceitação unânime no grupo de pensadores que coordeno e deixo então esta questão em aberto para mais reflexões, lembrando que não se trata apenas de um problema terminológico, mas conceitual. 
Ultimamente venho me dedicando ao estudo das relações entre imagens, visuais ou outras, por acreditar que a intertextualidade pode ser adotada como eixo para uma proposta pedagógica para o estudo de imagens. Para tanto, a leitura de imagens conforme aqui apresentada é fundamental, pois é indispensável a existência de grandezas comparáveis e Plano de Expressão e Plano de Conteúdo prestam-se para tal.

\section{Uma leitura (ou uma apreensão de imagem) a título de ilustração}

Independentemente da abordagem, cada imagem nos sugere como quer ser lida, ou apreendida. Cada imagem que "quer" ser lida, ou analisada, ou abordada, coloca-se diante de nosso olhar a nos seduzir. Por que dentre tantas, apenas algumas imagens selecionamos para estudar em detalhes? É que essas nos provocam, nos instigam, "falam" mais alto que outras, ou encontram em nós ressonância para o que "dizem".

Isto propicia montar não um estoque, mas uma pequena coleção de imagens para analisar quando oportuno. Assim, chegou a oportunidade de apreciar a fotografia de uma rua de Viena, aquela onde morou Sigmund Freud e que hoje abriga o museu com o seu nome. Com alunos, prefiro deixar para o final os dados, os créditos, para que eles não interfiram na leitura da imagem. Mas aqui não estamos em aula. 
Figura 1: Foto de Edmund Engelman no Sigmund Freud Museum, em Viena

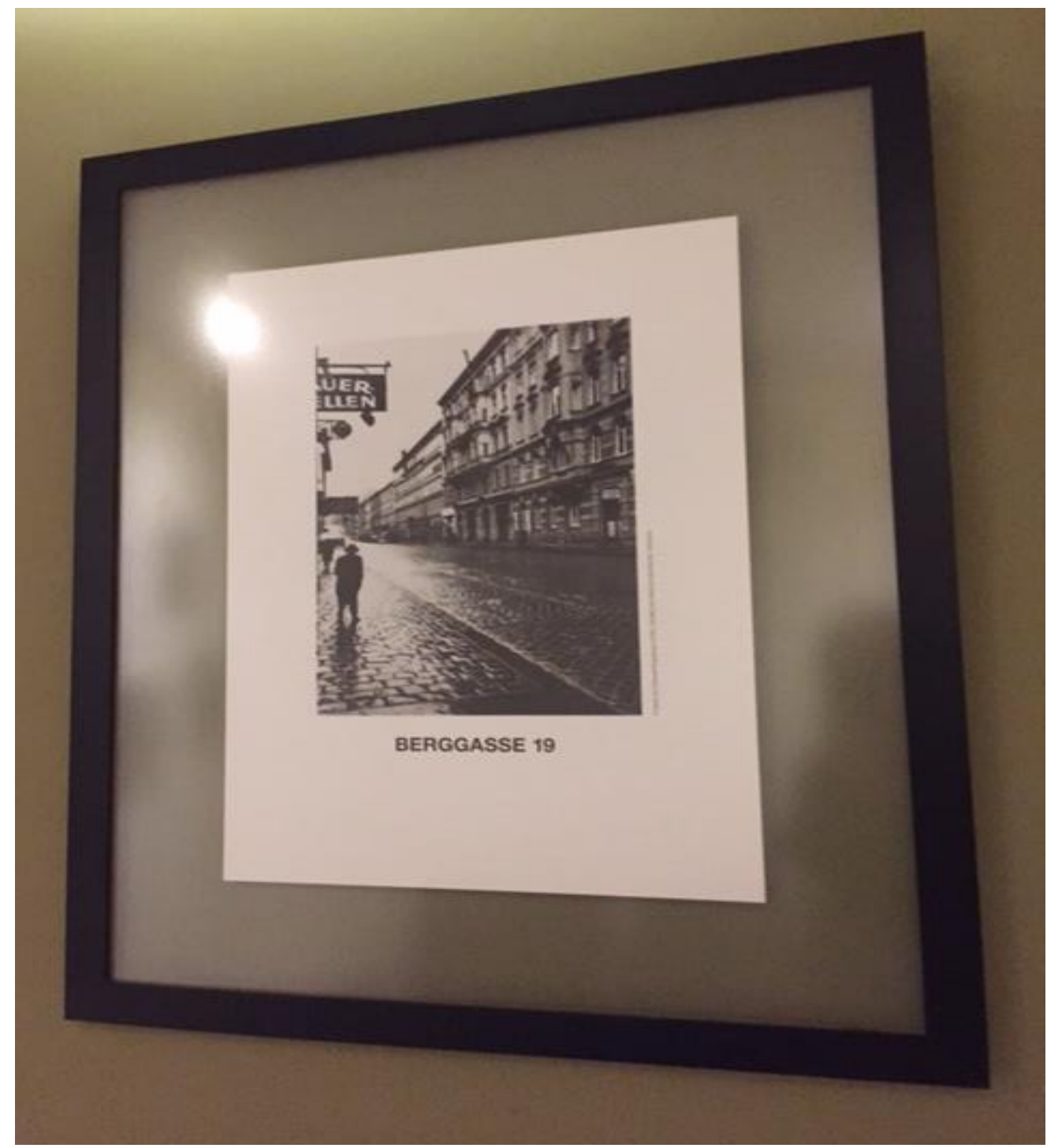

Fonte: Arquivo da autora.

A foto de Edmund Engelman é de 1938; embora o primeiro filme colorido moderno, o Kodachrome, tenha sido introduzido em 1935, não deveria ser de fácil aquisição e não se sabe se já era suficientemente difundido; assim, ignora-se se a foto é em $P \& B^{8}$ por opção do fotógrafo. Mas o importante é o que a imagem nos diz, e ela, dada a ausência de cor, que é reiterada por diversos outros aspectos, nos passa, de saída, efeitos de sentido disfóricos, negativos, como sendo predominantes.

Qual é a estrutura básica desta imagem? Um leque de diagonais. Ou um feixe de linhas retas diagonais que partem da esquerda, na parte inferior do retângulo e são

8 Sigla consagrada para se referir a fotos em preto e branco. 
como que atraídas para um ponto no lado oposto, à esquerda. Ou vice-versa, partem de um ponto à esquerda, acima da metade do retângulo que delimita a imagem, um feixe de linhas, direcionam-se para baixo e para cima, no sentido do lado oposto. Ou um triângulo, com a base vertical, coincidindo com o recorte lateral direito e o vértice na lateral oposta.

Quanto aos esquemas visuais, vários podem ser delineados: um evidenciando apenas os claros; por oposição, os escuros; outros, repetindo a estrutura básica tomada como opção de feixe de linhas ou triângulo; ou ainda um esquema contemplando os detalhes da calçada, o calçamento da rua, das fachadas e da figura humana única e, portanto, solitária na imagem.

Iniciando a análise do Plano de Expressão, examinam-se os elementos constitutivos e, a seguir, os procedimentos relacionais que se estabelecem entre eles. Entre os elementos, percebem-se três pontos de atenção: o ponto para o qual convergem o feixe de linhas ou onde se situa o vértice do triângulo, e o ponto de atenção que evidencia se tratar de uma figura humana, por seu contraste com o fundo e por estar em um plano mais próximo da visão do observador. Ambos são pontos que estão à esquerda, um praticamente sobre o outro, na metade da margem esquerda da imagem. Há um terceiro ponto de atenção, determinado pela proximidade do olhar do fotógrafo e, portanto, do olhar do observador da foto: uma placa escrita em um idioma estranho à interlocutora, o alemão; redunda em não dizer nada.

Quanto às linhas, são importantes para a significação per se e porque elas delimitam as formas. Percebe-se uma linha marcante, diagonal, que separa a calçada da rua. Há mais duas, convergentes para o mesmo ponto para o qual se dirige a primeira, uma no meio da rua e outra delimitando a calçada oposta das edificações. Encontram-se pequenas retas que delimitam o calçamento, formando inúmeros retângulos; na verdade, são diagonais. E há uma diagonal que é mais alta que o prédio onde está, talvez um mastro. Há as linhas também retas, que delimitam placas, talvez placas comerciais. Entre as poucas linhas que não são retas estão as que contornam o homem do plano anterior. 
Passemos então às cores, ao preto, matizes de cinza e branco, o que é inerente a uma foto $\mathrm{P} \& \mathrm{~B}$, talvez opção do fotógrafo, uma vez que já existiam filmes para fotos coloridas e sendo seu métier, ele deveria saber, o que leva a crer que se tratou de uma escolha. Além dos contrastes entre brancos e cinzas que determinam a visibilidade das texturas nas fachadas das edificações, uma grande área de tão branca parece brilhar. Ela começa em primeiro plano e vai se alargando na direção do fundo da imagem, para onde convergem também linhas perceptíveis ou sugeridas. Como que sugando pigmentos pretos e concentrando-os está uma figura humana, um homem de chapéu, de costas, traje escuro aparentando negro, caminhando pela calçada da esquerda, tendo atrás de si sua própria sombra. À sua frente, há uma outra figura, ou duas, indefinidas, supõe-se que seja uma figura humana e outra forma; assim descoladas da narrativa pela indefinição, fazem mais o efeito de sentido de cenário do que de personagem.

Embora se trate de uma foto, que anula as texturas táteis, há as texturas visuais, que nos são apresentadas ao olhar por mais um efeito da luminosidade. Entre as texturas mais evidentes na cena, estão as das fachadas das casas, da calçada e do calçamento da rua.

O principal procedimento relacional desta imagem é o contraste, entre o claro e o escuro. Outro contraste é o que se dá entre o que é construído pelo homem, como o traçado urbanístico da cidade e suas edificações e o ser humano. Este contraste pelo claro/escuro, é reiterado pelas linhas que o contornam. A dimensão do homem também contrasta com o comprimento da rua e o tamanho dos edifícios, mas ele reina sobre a cena, embora incógnito e misterioso.

Restringindo a análise a este procedimento relacional, o contraste, o qual é mais evidente embora existam outros, passemos ao Plano de Conteúdo, embora nele já tenhamos transitado, geralmente por meio de adjetivos: disfórico, negativo, incógnito, misterioso. Vemos um homem solitário, um pouco corcunda, um velho, provavelmente, por sua postura. Todo de negro, pouco de seu corpo está à mostra, e nada para quem o observa, pois ele está de costas. A luminosidade gritante da rua alude à ideia de que choveu, mas a chuva já passou. Ou seja, o tempo melhorou. E ele tem um caminho pela frente, um caminho luminoso, que o leva à ideia de infinito. 
A pessoa à sua frente viria ao seu encontro? Ou apenas lembra que ninguém está completamente só? A desconsideração do fotógrafo com as palavras da placa, cortando-as pelo meio, mostram que isto não é importante. Mas o quê não é importante? O consumo? As coisas materiais?

Associando-se essas coisas que estão no texto, acrescente-se questões relacionadas ao contexto, ao que se sabe, o título da foto: Berggasse 19; e os dados contidos na lateral da foto: Sigmund Freud Museum, Vienna, o que indica que o endereço é onde se localiza o museu, informação prévia que se tem. E o mastro na fachada talvez seja um marco que aponte para a localização exata. Trata-se de um museu-casa, onde estão guardados móveis, objetos e escritos de Freud, inclusive o icônico sofá do terapeuta.

Assim, podemos articular texto e contexto e apreender que um homem na escuridão dispõe de uma luz na sua vida e essa luz em perspectiva conduz ao infinito.

Tudo isto poderia ser dito se eu estivesse analisando apenas a foto de Edmund Engelman. Mas na verdade, estou analisando uma foto da foto tirada da foto de Engelmen, porque a imagem comercializada não é uma foto original. Trata-se de uma metalinguagem, duplamente: um novo texto visual, fotografando a fotografia; e o texto verbal que descreve e analisa a imagem e os sentidos produzidos por Edmund Engelman.

Eis então alguns aspectos a acrescentar à análise. Quanto à moldura, elemento significativo embora não constitutivo, aqui temos a observar diversas: a moldura de Engelman, que também coincide com o recorte da cena; a moldura do passe-partout branco, o qual contém o título da foto e em dimensão mínima, na lateral, possivelmente para não interferir, o nome do museu, do autor e a data, talvez escolha da gráfica ou outra empresa que comercializa a foto; outro passe-partout de vidro transparente, com uma moldura preta como uma régua, escolha significante do sujeito que adquiriu a foto e colocou-a em uma parede. Dada a transparência do vidro e a cor cinza da parede onde foi afixada a foto, agora em um quadro, há uma outra moldura cinza, delimitada por uma última, na cor negra. Há uma coerência cromática nas 
camadas de efeitos de sentido sobrepostas à fotografia, pois elas oscilaram do branco ao preto, passando pelo cinza, assim como a foto.

Considerando-se ainda os dados estéticos presentes na foto da foto, percebese também algumas luzes refletindo no vidro: à esquerda, um foco circular no alto e manchas de luz e sombra mais abaixo. À esquerda, há um vulto escuro, parecendo uma figura humana, delineada pela luz que lhe serve de fundo. Tudo isto aparece no passe-partout, em volta da imagem, ou na sua moldura, em um sentido amplo.

O vulto que aparece sobre o vidro, dada a existência de uma luminosidade por trás de si, é de quem bateu a foto do quadro, o qual está na sala de espera de um terapeuta. Aqui se estabelece uma relação entre luz e sombra no contexto do texto da foto da fachada do museu-casa de Sigmund Freud e a situação onde se encontra a foto de Engelman. Se o facho de luz na Rua Berg (Bergstrasse) indica um caminho iluminado para o sujeito na sombra, gerando outra sombra, um duplo, do mesmo modo alguém em um consultório psicológico deve estar buscando luzes para os seus eus, divididos e plurais, seu eu escuro, misterioso e incógnito: uma luz na escuridão.

\section{Considerações}

O título deste texto já prenuncia que há em questão uma oposição semântica de base, binária, portanto, entre luz e escuridão, ou entre claro e escuro: fotografia é luz. A metáfora se reveste, primeiro, da questão do saber, presentificado pela luz, pressupondo as trevas como a ignorância, no sentido de não saber. E então, o pensamento é desviado, para a possibilidade de a luz poder conduzir para o acesso aos bens estéticos produzidos socialmente, mas nem sempre socialmente acessíveis. Essa foto, para o senso comum, por seus efeitos de sentido disfóricos, isto é, tristes, negativos, poderiam gerar rejeição. Mas uma análise mais acurada pode dar acesso à apreensão de elementos estéticos outros, que acrescentam percepções a um olhar primeiro ou apressado.

Para esta tarefa, adotei o mesmo modelo de análise concebido há vinte anos, cuja "existência" operou, além dos seus objetivos, algumas distorções e elas aqui são 
também discutidas. Então, concluo com a leitura de uma imagem, a título de exemplificação do modelo de análise.

Concordo que leituras - ou apreensões, análises, ou interpretações, etc. podem ser retoricamente mais sofisticadas, historicamente mais precisas, socialmente mais críticas, mas não acredito que sejam textualmente mais comprometidas, pois as demais terão partido de dados extratextuais. O estudo do uso de elementos da linguagem visual e de procedimentos estéticos que correlacionam esses elementos gerando imagens e seus efeitos de sentido, que são textos visuais, em processo análogo àqueles que articulam sintaticamente classes de palavras para gerar textos verbais, acredito poder contribuir para que a maioria da população possa acessar às imagens de modo mais crítico, emancipado e liberto, com vistas à consolidação da sua cidadania.

\section{Referências}

HJELMSLEV, Louis. Prolegômenos a uma teoria da linguagem. São Paulo: Perspectiva, 2001. LANDOWSKI, Eric. O olhar comprometido. Galáxia, São Paulo, n. 2, p. 19-56, 2001.

LANDOWSKI, Eric. Para uma semiótica sensível. Educação \& Realidade, Porto Alegre, n. 30, n. 2, p. 93-106, jul-dez 2005.

LANDOWSKI, Eric. Com Greimas: interações semióticas. São Paulo: Estação das Letras e Cores, 2017.

OLIVEIRA, Ana Claudia. Visualidade: entre significação sensível e inteligível. Educação \& Realidade, Porto Alegre, n. 30, n.2, p. 107-122, jul-dez, 2005.

RAMALHO E OLIVEIRA, Sandra Regina. Leitura de imagem para a educação. São Paulo: PUCSP, 1998. Tese (Doutorado em Comunicação e Semiótica). Programa de Pós-Graduação em Comunicação e Semiótica, Faculdade de Filosofia, Comunicação, Letras e Artes, Pontifícia Universidade Católica de São Paulo, São Paulo, 1998.

RAMALHO E OLIVEIRA, Sandra Regina. Imagem também se lê. São Paulo: Rosari, 2010. 2a reimpressão.

RAMALHO E OLIVEIRA, Sandra Regina. Imagem também se lê. In: DA ROS, Silvia Zanatta; MAHEIRIE, Kátia; ZANELLA, Andréa Vieira. (Orgs.). Relações estéticas, atividade criadora e imaginação: sujeitos e (em) experiência. 1ª. ed. Florianópolis: NUP/CED/UFSC, 2006. p. 209-220.

RAMALHO E OLIVEIRA, Sandra Regina. Sentidos de uma teoria do sentido no campo das linguagens visuais. In: OLIVEIRA, Ana Claudia de. (Org.) Do sensível ao inteligível: duas décadas de construção do sentido. São Paulo: Estação das Letras e Cores, 2014. p. 195-210. 


\section{Sandra Regina Ramalho e Oliveira}

Doutora em Comunicação e Semiótica pela PUC São Paulo (1998), com pós-doutoramento na França, em Semiótica Visual (2002). Pesquisadora e professora da Universidade do Estado de Santa Catarina/UDESC, atua na Graduação e no Programa de Pós-Graduação em Artes Visuais como professora e orientadora. Autora dos livros Imagem também se lê, Moda também é texto, Sentidos à mesa e Diante de uma imagem, organizou, em coautoria, oito outros títulos de livros. Foi Coordenadora do Programa de Pós-Graduação em Artes Visuais da UDESC, Presidente da Associação Nacional de Pesquisadores em Artes Plásticas (ANPAP 2007-2008) e é consultora da CAPES.

E-mail: ramalho@floripa.com.br

Currículo: http://lattes.cnpq.br/0870589343786662

Recebido em 9 de março de 2018

Aceito em 9 de abril de 2018 